\title{
Community-Engaged Scholarship and Promotion and Tenure: Lessons from Lynton Award Recipients
}

Elaine Ward

In 2008, for my dissertation research, I interviewed eleven faculty members who received the Ernest Lynton Award for the Scholarship of Engagement to examine their experiences with promotion and tenure. There were three assistant professors, one associate professor, and seven full professors. All faculty members were female and represented eight four-year public institutions (four RU/VH, two Master's and two Doctoral Granting Universities) and three fouryear private institutions (two Bac/A\&S and one RU/VH). They represented the humanities (eight) and the sciences (three). Through qualitative, semi-structured, opened-ended interviews, I aimed to understand their experiences with engaged scholarship in the context of promotion and tenure.

Many community-engaged scholars fight to receive the internal validation that Ernest advocated for with Amy Driscoll via Making Outreach Visible: A Guide to Documenting Professional Service and Outreach (1999). Ernest might be somewhat content to know that the award in his name provides external validation that helps legitimize their scholarship at their home institution. I say 'somewhat content', for it is clear that Ernest had high expectations for institutions to value the work of engaged faculty. Amy Driscoll helped to advance Ernest's vision through her leadership of the collaborative process of that produced the Carnegie Elective Classification for Community Engagement (2008), and its requirement that applicants must show how they address promotion of community-engaged scholarship formally via personnel policy, i.e., faculty handbooks and contracts. While we find more evidence of rewards that value communityengaged scholarship, broad and consistent equivalence of recognition and rewards across all faculty roles will require further effort and commitment.

\section{Community-Engaged-Scholars Experiences with Promotion}

The following is an excerpt (2010) from my dissertation research. It synthesizes individual narratives from my interviews with Lynton Award recipients prior to 2010. The excerpt conveys a shared understanding of their engaged scholarly work, influences, motivations and intersections with institutional culture via promotion and tenure policy and processes. The resulting narrative combines direct quotes from the faculty members and my own synthesis of aspects of their narratives to summarize their experience. Their individual experiences, along with the post-tenure reflections of more authors in this special issue contribution may lead us to a deeper understanding of their significance for the broader development of institutional reward systems and policies that more fully realize Ernest's mission to validate and legitimate professional service/community-engaged scholarship. Lynton's work will have achieved success when there is an 'equivalence of recognition' across teaching, research and engagement (Lynton, 1993, Metropolitan Universities/Summer 1993; Lynton, 1996a; Driscoll and Lynton, 1999).

Elaine: For me, community-engaged scholarship is work grounded in and motivated by the needs of those outside the academy by real people dealing with real problems in the 
real world. Community-engaged scholarship is ideally about strong, trusting, respectful and reciprocal relations that last the test of time and results in collaborative projects that lead to community and social change and good scholarship. That is the essence of mutual benefit in engagement between the academy and the public. When in reality communityengaged scholarship is a messy practice, filled with negotiating multiple needs and wants, translating across multiple languages (institutional and organizational rather than linguistic), figuring things out as you go, and often bears multiple surprises and disappointments. As a faculty member, we are often in the difficult position of never being able to please everyone - we cannot please our students from the outset when we don't present ourselves as the all-knowing expert or by not being able to foresee all the obstacles and challenges that will inevitably arise. We cannot always please our nonengaged colleagues because the focus is not on their value of detachment, and we often struggle to be recognized by the traditionalist reviewers of our promotion and tenure committees. Can we talk about your community engaged scholarship and your experiences with promotion at your institution?

Maura: For me-I'm just going to speak from my heart—community-engaged scholarship is where you yourself are truly a part of the community. You may not be from that community...but you yourself have become part of that community.

Karen: I agree with Maura, engagement has to be a sustain effort. It cannot just be a onenight stand. It means making a commitment each and every semester. I often joke with my students - I wish poverty went away this semester. I wish domestic violence went away this semester. So, for me engagement means making a commitment each semester for the past 23 years. And this cannot happen if we have a purely academic orientation to our work.

Elaine: What is the orientation that is needed for authentic engagement build on values of trust and participation?

Karen: For me, it's a conscious political position that opposes an institution-centric perspective, where I use the tools of my academic trade as a means to accomplish social justice ends and community ends.

Ruth: Yes, the community has to be in the driver's seat. The work of social change has to begin at the grassroots. Change that is brought from the outside, without collaboration or analysis from beneficiaries, without their input, is dead on arrival. I want to stress the point that even though we might be scholars or researchers, the people we work with are experts in their own situation and are more able to tell us about their reality than we can ever understand.

Susan: I agree that the community is a source of knowledge and I also believe that our students bring more reality to the classroom than is often recognized in the academy. I view engaged research as a collaborative process where I and the people I am working with are co-researchers, co-beneficiaries, co-creators of the research. So research is a many centered knowledge production process that honors different kinds of 
epistemologies and all ways of knowing. My classrooms are a collaborative, many centered knowledge production space.

Jennifer: My experience is a little different in that the point of my work is not necessarily to be community-driven, but it certainly is to be practically-driven. I want to do the most rigorous theoretical and methodological work that I can, but I have to have a practical purpose. My work in the academy is driven by my job in the workforce prior to becoming a professor. My job is not to go out and demonstrate expertise as much as to demonstrate problem-solving and to guide effective communication and team work.

Elaine: The creativity of your individual work speaks to your attempts to recognize and include multiple and diverse ways of teaching, learning, inquiring, knowing and doing. The relational, connected, and collaborative processes help keep this work true to the values of mutuality and reciprocity that we individually and collectively hold dear. What else motivates your community-engaged scholarship?

Shanna: It is about a sense of fairness. Why should children in the poor school not have the same access to resources as the children in the private school? In general, public schools have the will and the interest, but not always the capital to provide resources. It is this inequity that motivates me to work for change and provide more equitable resources.

Catherine: For me, as a child of the 1960s, I was always involved in working for change. From a child, I was involved in community organizations and in high school community advocacy projects. My parents were both very strong community leaders.

Susan: I can relate to that. I too grew up watching my parents helping people to improve their education and their lives. When I was little, I used to go to the center where my mother worked as a social worker. So, I was trained very young to be interested in social issues. But it wasn't until I went to work in the community that the question came to me for the first time, what is the purpose of my academic research? What do I really want to do with it? Just get a doctorate? If that was the case, I don't think I ever could have finished. Honestly, because it has no meaning or relevance. I need to make my research relevant.

Lucinda: Similarly, I questioned the relevancy of what I studied in graduate school. The 'so what' question got me, and I wondered if anything I was doing was relevant to anyone other than me and my small academic community.

Maura: Diversity is key for me. My diverse, multiracial and multi-cultural background is an important piece of my community engagement work. My personal difficulties motivate me to work toward equity in the sharing of resources. Issues of diversity and equity are the fundamental components of my engagement work.

Karen: Social justice is a huge motivator for my work. I use my academic work to advance my activist work where I work for change in local and international communities. 
Ruth: For me too, social justice is one of the three main drivers of my community engagement.

Jill, Eleanor, Catherine: I agree.

Elaine: There is an overwhelming consensus that social justice and community change are reasons for you doing community-engaged scholarship.

All: Yes!

Eleanor: And our beliefs about knowledge generation and sharing. I believe in learning that works. So diverse, dynamic learning networks that include all community members, in my experience, are one of the more powerful ways of formulating and testing new theories and perhaps more importantly refining practice and making real change in the world.

Karen: Yes, and for me epistemology connects to the political. The feminist, conscious political choice becomes a part of the way of thinking, living and teaching. It shapes knowledge production and views. I believe that it also shapes research and your social process too.

Elaine: So, are you saying that there are personal and public dimensions to our beliefs about knowing and learning and that these have a political dimension?

Maura: Yes, my ways of knowing are very personal to me. Then I discovered scholarship I could relate to it. I could give language to what I already knew in my spirit. To give it language legitimatized it.

Ruth: Yes, there is a political dimension. There are all these issues of power, especially in Western societies where the contributions of women are not very valued.

Lucinda: Even locally, the issues of power and voice are prevalent. It $i$ s power. People are used to listening to people who can speak a certain language, and part of this is academia. So, I see my role to translate between the community and the academy. Its raising awareness and translating that voice.

Shanna: For me, epistemology and gender are connected, and both serve as a mirror to the power dynamics that exist in the academy. As a woman in a male-dominated field, I realized that being a woman to an extent was a liability. Professors wielded their power by telling me that I didn't belong in the classroom or I wasn't smart enough. This influenced my sense of confidence for a while, but then I got angry, and now I've just come to terms with it.

Susan: There are others who have gone before us, not in the field of engagement, who talk about this politics of epistemologies. For example, Nadine Cruz. She talks about 
different ways of knowing, and Laura Rendon talks about integration, spirituality, and liberation. These things make a huge impact on my own thinking. So, I try to honor different kinds of epistemologies or like Nadine Cruz would say 'all ways of knowing' in my own teaching and research.

Elaine: When we talk about our personal epistemologies, like when we talk about gender, we are talking about our identity - the very essence of who we are. The language that we use to talk about this is very emotional and very personal. I appreciate you sharing about yourselves in this way. It is not a level of conversation that happens very often in academia.

Susan: Yes, and I'd like to revisit what Shanna said about the connections between gender and epistemology and I would like to try to connect this more directly to identity and institutional culture. We are trying to survive in a very masculine academic culture. It is this culture where you are expected to take on this identity as the expert in everything and that you don't show emotions, that you don't embrace reflective thinking. Having to survive those expectations is difficult and they are very much at odds with what I value and think are important.

Audrey: Yes, navigating these issues of personal identity, values, and epistemology in the academy is tough. We have to protect ourselves and think strategically about what work we do publicly.

Elaine: Audrey, your experience raises issues about the culture of the academy and the subsequent expectations placed on us. Let us explore the intersections between our individual faculty work and your institutional cultures and contexts. What are your experiences as a community-engaged scholar? Where are there alignments and divergences? Themes I have noted in our conversations include: the work of engagement is versatile enough to happen across the disciplines, faculty members experience both hostile and hospitable environments that either reject or reward their engaged scholarly work, and that there is as much rhetoric regarding practice as there is adherence to existing policies. Let's start with these.

Shanna: I agree that this work can happen across the disciplines and also across institutional types. Some people say that service-learning is more conducive to liberal arts institutions, liberal arts disciplines than to science. I do not believe that. I just think it is how you frame what you do and what you define as a connection with community.

Catherine: And how we frame what we do is critical in the promotion and tenure process. I navigated the tenure and promotion process by looking at the mission statements of the university and the college and if this is what the mission says then that is what I grounded my work in. I did not assume that people remembered the mission or guidelines, so I reminded them. I just followed the rules. 
Eleanor: That is wonderful that you had such clear protocol to follow. I only wish we all had. I constantly got mixed messages about what I should do or should not do for tenure. I still don't know where I stand.

Maura: I made sure I had two research agendas: one for me and one for the academy. I was very strategic and published a lot.

Shanna: I too had two research paths. And I also I think we have to be a lot more loose about what I would term scholarship, because I think scholarship depends on who you are speaking with. Inside the Ivory Gates I think they are looking at specific parts of scholarship for example books and papers. But I would really consider a [designed community space] a product of scholarship because it is the [user's] knowledge and way of knowing and ways of [using the space] and the members of the community in addition to us [academics] that we are all working together to try to address a critical community issue in a specific way. I want to see how we are using scholarship to improve equity in resources.

Lucinda: I have a very supportive chair and department. I am not worried. Engagement is part of the President's vision for the college.

Jennifer: They could have denied me tenure, but given what was on the record, I always felt pretty secure. But I have to say, they had my portfolio reviewed by one of their friends who never finished his $\mathrm{PhD}$. I am going up for promotion at a research institution and the committee chose to send it to one of their friends who never finished his degree. That was a slap in the face!

Susan: I received messages that I should not include certain work in my $4^{\text {th }}$ year review, but I did. It was important to me to have my voice on record, but for tenure, I took this out. I wanted to get 'in' before I engaged with people around this. It was a tactical move, but a painful one.

Shanna: I can relate to this sense of pain through the tenure process. I had both traditional research and engaged research in my portfolio, but this did not matter. I had a very supportive chair and I was nurtured and encouraged. Then the chair left. Even with the support of the new chair the promotion and tenure committee voted against me. I had zero votes for, 2 votes against and one person abstaining. Even though I had 15 refereed journal articles - my college said if you had 10 you'd be safe - I had 1.5 [projects] completed. I mean all you had to do was count. If promotion and tenure is bean counting, which to an extent it is. I had the numbers. I think essentially what happened was that the woman who was a year ahead of me had trouble with promotion and tenure. We were wonderful friends. We collaborated a little bit and we supported each other. But once I started getting recognition - essentially for doing service-learning - I think she just got really disgusted somehow and so she really led the charge against me going up for promotion and tenure. They wrote in their faculty report that my case was going to be a test for whether the University really valued service learning and scholarship, and because they said that my quote, un-quote, traditional research did not stack up. I got 
through because I had a lot of external support. I wrote an appeal letter and I probably had the best, most well-crafted piece of writing I have ever done in my life because I literally had six English professors looking at it and offering me suggestions. So, I made it, even with the negative vote in the department, because every single vote after that [favored my case].

Karen: Yes, in academia you are still measured by your publications. Your prestige is related to that. Activist work can result in publication, but it is marginalized in academia and anyone who chooses to be an activist is more marginalized because it is not respected. It is not viewed in the same way as conventional teaching or conventional research. Any time I did anything as an activist scholar, which I always did, I was delegitimized as a scholar.

Shanna: It can be a double-edged sword, right? Where you do community engagement and you get a lot of public recognition, you develop your relationships with your administrators who wind up saving you in the end when the faculty cuts you because you are doing community engagement!

Elaine: Susan, you talked about strategic decisions you made about what to present in your dossier as you moved through stages of promotion so that you would "fit in". Have any others made strategic choices as you have moved through the stages? Do we see the risks for the engaged scholar lessening as you move through the faculty ranks?

Shanna: Yes, I tried really hard not to highlight my community engagement going from assistant to associate because I did not think my department really would understand it. So, I really focused a lot more on the traditional [research]. When I went up for full, I was absolutely unapologetic about it. I mean I have a bigger reputation in [engaged research] than I do in traditional research and it is a huge impact in terms of what I do so it figured prominently in my write-ups. I tell you one thing I was nervous about was finding external evaluators in my field that I thought would understand [my work]. My chair was helpful. He said, "you know you are doing this traditional [research], and you are doing this teaching [research] and there has never been officially a teaching research portion of your job description. I want to change your job description so that when you go up for full and external evaluators are looking at your records, they are going to see that teaching research is officially part of your position." I sailed through.

Elaine: Your experiences highlight the intersections between personal and social identity, commitment to social change and your professional work in the academy. Knowledge production is the work of the academy and the work of the faculty, but you are pushing on the boundaries of what are accepted as legitimate sources and methods of producing and sharing knowledge. Our personal epistemologies become our public epistemologies as we enter into the debate of the politics of knowledge and the power relations and dynamics associate with knowledge production and sharing. All the while, we want to ensure that what we do and how we do it practical and relevant in nature, clearly articulated, and serving of a purpose greater than our discipline, our institution or ourselves. As we continue our engaged scholarly work, our hope is that our institutions 
grow in their ability to support the multidimensionality of our work through faculty reward policy and practice.

(Ward, E., 2018)

\section{Lessons}

Decisions to carry out community-engaged scholarship are deeply rooted in a faculty member's identity.

Data from this study connects the faculty members' intersecting identities with their motivations for beginning and sustaining community-engaged scholarship. The faculty members often define, re-define, share and re-shape their identity as scholars and civic agents as they attempt to realize their fullest selves and potential in their academic institutions. Community-engaged scholarship is a manifestation of the scholar's integrated sense of personal, civic, and professional identities. The faculty members in this study claim social identities that go beyond mere connection to society and culture (Hurtado, 1996), but own a sense of civic or political responsibility and democratic purpose (Dzur, 2008; Sullivan, 2000; Code, 1991; Naples, 2003). The faculty members also claim a strong professional or scholarly identity, influenced by their faculty roles, one's discipline and academic epistemologies. Each faculty member claims multiple and intersecting identities, stemming from their race, ethnicity, socioeconomic background, sexual orientation, parent, scholar, practitioner, teacher, inquirer, thinker, and knower. Their personal, civic, and professional identities result in an integrated identity, manifesting in a sustained commitment to exemplary community-engaged scholarship.

Sources of personal identity can include gender, race, ethnicity, sexual orientation, socioeconomic background, and personal epistemological orientation (i.e. intuition, emotion, value driven ways of knowing and constructing knowledge, deconstructing dominant epistemologies). Sources of professional identity relate to faculty roles - teaching, learning, service, or inquiry, as well as disciplinary affiliation, and academic epistemological orientation. In the case of some of these scholars, it leads to a rejection of dominant epistemological orientations). Sources of civic identity comprise a sense of connection to and responsibility for favored groups or causes, community, church/faith, social justice, participatory democracy, democratic inclusion, and engaged epistemology.

\section{Connectedness}

Our motivations for, and conduct of, community-engaged scholarship emerge from not only our identity, but also our identity in context. The contexts for engaged faculty vary, yet have similar characteristics across space and place. The overarching concept of connectedness helps us understand that engaged faculty members work from existing connections to place, with people, and, for some, to political action. They relate to place through a strong sense of rootedness and deep belonging. They form connections with others through a strong commitment to real and reciprocal relationships that enhance that sense of belonging. Moreover, they connect to the need for political action through a strong sense of responsibility to act on behalf of self and others to ensure equity, fairness, and justice for all those who belong to their respective community. The 
concepts of connectedness and belonging are essential to any understanding of community. They may apply locally, nationally, and globally. Meanings and geographic boundaries of community differ for each faculty member, which points to the socially constructed nature of community.

Epistemological orientation matters i.e. epistemology influences engagement

Knowing that for the majority of faculty members in the study, engagement is deeply personal and connected to their core identity: who they are as a person, scholar, and civic agent. Epistemological orientation is the one source of identity present in each of the three facets of their identity. As a community-engaged scholar, the faculty claim a personal epistemology and an engaged epistemology. They also take hold of the academic epistemology of their department and institution.

Negotiating these multiple epistemologies requires a commitment to an improved state of being. Nadine Cruz (2009) contends that the core issue in the politics of engagement requires a reframing, away from the dominant expert epistemology of the academy and a recognition of the significance of ontology in the work of civic or community engagement. She calls for not only epistemological transformation, but also pedagogical and institutional transformation that recognizes a battle of ideas and that the real driver, along with what we want to know, is how we want to be in the world or ontology.

I argue that the this study's community-engaged scholars cared very much about how they and their communities would be in this world, what services they have access to, and what quality of life they would live. They also deeply care about their own lived experiences in the academy, as well as an accord with their experiences there and their own personal values. The goal is for their epistemological, methodological, and pedagogical approaches to echo their ontological values. This is clear from Karen's statement about her academic scholarship as a means for her to achieve her "social justice and community ends." She has a distinct vision about how the women and the communities she works with should live their lives and reach their fullest potential. Karen questions the systems that prevent such a quality of life for the women she shares that goal. Using the "tools of her trade", she has adapted and developed her epistemological and methodological values to effect positive change for the women with whom she works. Karen pushes against the expectations the institution has for her as a scholar. She does the work she needs to do, in the way she needs to do it, to effect the change she wants to see in the world.

Ernest Lynton challenged higher education to respect and value community engagement as legitimate scholarly work. Unfortunately, we see that faculty members in this study, as well as those who contribute their post-tenure reflections, fight to preserve their personal epistemological values in institutional environments that are often hostile toward non-traditional ways of knowing. Yet the hope is in the fact that many engaged scholars stay their path even they have to battle the 'cult of the academy'. They are willing to take on this fight because they cannot in good conscience compromise their convictions. The Lynton Award recipients have paved the way for the next generation of engaged scholars who "do not compromise objectivity for the sake of pure science but rather value individual experience in addition to the legitimacy of the collective." (Ward, 2016, p. 111) 
Ward \& Miller (2016, p. 184) recount that:

[Engaged scholars share a] collective unease with the existing normative structures, cultures, and practices of higher education that diminish academia's responsibility as an institutional steward of place, where the institution extends its fullest resources to advance public purposes... and [w]e become stewards of change as we call for a transformation of higher education that legitimizes the contributions of communityengaged scholars and more fully responds to the transdisciplinary nature of knowledge that is equitably co-created in and with community.

Tenure allows free practice of community-engaged scholarship, and institutional influence comes with promotion to full professor.

To what extent a faculty member shares or conceals their work depends on their rank. Faculty members in this study, and those sharing their post-tenure narratives, are often in self-protection mode where they conceal their efforts from others within their institution to protect their work from being undermined or compromised. Many faculty members stay under the radar or have multiple research agendas. The strategic stealth required at the pre-tenure stage often does not dissipate until the faculty member has achieved the rank of full professor. At this stage of a career, a faculty member will experience safety and subsequent freedom to be fully open about their work. This freedom also bring a level of authority. Audrey, Shanna, Jennifer, and Karen share how they still surprise themselves by the amount of influence they hold as senior faculty members. Their counsel carries weight at the institutional level and beyond. Often these faculty members serve as consultants to other institutions that seek to align promotion and tenure policies with community-engaged scholarship, as is the case with Shanna. We see similar reflections in the contributing authors in this special issue.

The faculty members in this study worked at institutions either hospitable or hostile toward community-engaged scholarship. Teaching-focused institutions provided more supportive academic homes than research-intensive institutions. The mission of the Metropolitan University is to serve the region, and therefore one might hope to find more supportive institutional policy and practice related to the recognition and reward of community-engaged scholarship at CUMU institutions. Even so, the decisions the faculty member makes about navigating their respective institutional context, establishing key alliances, aligning their work with the institution's mission (Lynton, 1996b), and clearly framing one's promotion portfolio are all key contributions to a successful review.

Once awarded tenure, many community-engaged faculty members solidify their commitment through mentoring the next generation of community-engaged scholars and students, opposing the dominant paradigm, centering marginalized standpoints, and advocating for institutional change that amplifies commitments to engagement. The contributing authors advance Ernest's legacy via their stewardship of change in similar ways through their post-tenure narratives. 


\section{References}

Code, L. (1991). What can she know?: Feminist theory and the construction of knowledge. New York: Cornell University Press.

Cruz, N. (2009). Presentation. University of Massachusetts, Boston.

Driscoll, A. (2008). Carnegie Foundation for the Advancement of Teaching. Retrieved from http://www.carnegiefoundation.org/.

Driscoll, A. \& Lynton, E. (1999). Making outreach visible: A guide to documenting professional service and outreach. Washington, DC: American Association for Higher Education.

Dzur, A. W. (2008). Democratic professionalism: Citizen participation and the reconstruction of professional ethics, identity, and practice. University Park: The Pennsylvania State University Press.

Hurtado, A. (1996). Strategic suspensions: Feminists of color theorize the production of knowledge. In Goldberger et al. (Eds.) Knowledge, difference, and power: Essays inspired by women's ways of knowing (pp. 372-392).

Lynton, E. A. (1993 summer). From the editor's desk. Metropolitan Universities, 4 (2), 2-5. Retrieved from https://journals.iupui.edu/index.php/muj/article/view/19646/19349

Lynton, E. A. (1996a). Ensuring the quality of outreach: The critical role of evaluating individual and collective initiatives and performance. Journal of Public Service and Outreach, 1 (2), 16-22. Retrieved from https://eric.ed.gov/?id=EJ1097203

Lynton, E. A. (1996b Winter). Reversing the telescope: Viewing individual activities within a collective context. Metropolitan Universities, 7 (3), 41-45. Retrieved from https://journals.iupui.edu/index.php/muj/article/view/19571/19276

Naples, N. A. (2003). Feminism and method: Ethnography, discourse analysis, and activist research. New York: Routledge Press.

Sullivan, W. M. (2000). Institutional identity and social responsibility in higher education. In Ehrlich, T. (Ed.). Civic responsibility and higher education (pp. 19-37). Westport, CT: American Council on Education, Series on Higher Education, Oryx Press.

Ward, E. (2010). Women's ways of engagement: An exploration of gender, the scholarship of engagement and institutional reward policy and practice. Doctoral Dissertation. University of Massachusetts, Boston.

Ward, E. (2016). Section II: New public scholars. In M. Post, E. Ward, N. Longo, \& J. Saltmarsh (Eds.). Publicly Engaged Scholars: Next Generation Engagement and the Future of Higher 
Education (pp. 111-115). Stirling, VA: Stylus Publishing.

Ward, E. \& Miller, A. (2016). Next-generation engaged scholars: Stewards of change. In, M. Post, E. Ward, N. Longo, \& J. Saltmarsh, J. (Eds.). Publicly engaged scholars: Next-generation engagement and the future of higher education (pp. 184-193). Stirling, VA: Stylus Publishing. 


\section{Author Information}

Elaine Ward, Ed.D.

Merrimack College

315 Turnpike Street

North Andover, MA 01845

Telephone: (978) 837-3572

Email: warde@merrimack.edu

For almost ten years, Dr. Ward has worked with faculty nominees and recipients of the Ernest A. Lynton Award for the Scholarship of Engagement for Early Career Faculty, served as the award coordinator and has chaired and co-chaired the Annual Lynton Colloquium. Dr. Ward writes and teaches on the institutionalization of civic and community engagement within higher education as is co-editor of the book Publicly Engaged Scholars: Next Generation Engagement and the Future of Higher Education (2016). Dr. Ward was also one of the leads on the international pilot of the Carnegie Elective Community Engagement Classification in Ireland. Dr. Ward has served on the board of the International Association for Research on Service Learning and Community Engagement and was the conference program chair in 2016, Reaffirming Our Purpose, Bridging Our Understandings \& Broadening Our Collective Impact. Currently, Dr. Ward is an Assistant Professor of Higher Education at Merrimack College, School of Education and Social Policy. 